Article

\title{
Food Waste Generation at Household Level: Results of a Survey among Employees of Two European Research Centers in Italy and Germany
}

\author{
Juliane Jörissen *, Carmen Priefer ${ }^{\dagger}$ and Klaus-Rainer Bräutigam ${ }^{\dagger}$ \\ Institute for Technology Assessment and Systems Analysis (ITAS), Karlsruhe Institute of Technology \\ (KIT), Karlstraße 11, 76133 Karlsruhe, Germany; E-Mails: carmen.priefer@kit.edu (C.P.); \\ klaus-rainer.braeutigam@kit.edu (K.-R.B.) \\ $\dagger$ These authors contributed equally to this work. \\ * Author to whom correspondence should be addressed; E-Mail: juliane.joerissen@kit.edu; \\ Tel.: +49-721-608-22994; Fax: +49-721-608-24806.
}

Academic Editors: Kirrilly Thompson, Drew Dawson and Anne Sharp

Received: 19 January 2015 / Accepted: 2 March 2015 / Published: 5 March 2015

\begin{abstract}
There is a broad consensus in literature that private households are significant contributors to the total amount of food waste in the EU. Thus, any strategy to meaningfully combat food wastage must put the end consumer in the center of prevention activities. This requires deeper insights into people's motivations to discard still edible food and knowledge about potential barriers to reduce wasting. This paper reports on results of an online survey among two European research centers in Italy (JRC/Ispra) and Germany (KIT/Karlsruhe). The focus of the survey was on households' behaviors (shopping, eating, and food preparation habits) and its influence on the generation of food waste. Furthermore, reasons for the disposal of food as well as measures and technologies most needed to prevent wastage were discussed. The results of the survey are analyzed, especially with regard to two questions: (1) Are there considerable differences between Ispra and Karlsruhe? (2) Are there considerable similarities or inconsistencies with the results of previous studies?
\end{abstract}

Keywords: food waste; households; survey; consumer behavior 


\section{Introduction}

The reduction of food waste is seen as a key lever for achieving global food security, freeing up finite resources for other uses, diminishing environmental risks, and avoiding financial losses [1-5]. The food waste issue is currently high on the political agenda in Europe. In its roadmap for a resource efficient Europe, the European Commission has set a target to halve the disposal of edible food by 2020 [6]. In the context of the forthcoming revision of the European Waste Framework Directive (2008/98/EC), the Commission plans to commit the Member States to reduce their food waste by $30 \%$ before 2025 [7].

Quite a large number of studies on the scale, causes, and impacts of food waste generation in EU-27 have been carried out in recent years. National surveys are available for Great Britain, the Netherlands, Denmark, Sweden, Finland and Norway, France, Italy, Portugal, Germany, Austria, and Switzerland. National research activities as well as political initiatives mainly originate from Western, Central and Northern Europe. Some Southern and most of the Eastern European countries are scarcely present in the actual debate. Studies on food waste have been published by a variety of different institutions. These include universities, research institutions, NGOs, industrial companies, national ministries, international, and European organizations. However, the findings of different studies vary greatly, even if they are dealing with the same subject, and can hardly be compared due to different assumptions regarding the definition of the terms "food loss" and "food waste", system boundaries, design and scope of investigation, and methods used for data collection and analysis. Some studies cover all kinds of food waste; in others, the non-edible parts of food items are excluded. Some studies measure food waste as a percentage of consumed calories (e.g., [8]), others as a percentage of the weight of food purchased (e.g., [9]) or of the weight of domestic waste (e.g., [10-12]). Still others measure the amount of food being wasted in monetary values (e.g., [13]).

Although the assessment of global food losses along the supply chain is based on highly uncertain data, there is no doubt that considerable quantities are at stake. The Food and Agriculture Organization of the United Nations (FAO) estimates that roughly one third of the food produced for human nutrition is lost or wasted globally, which amounts to approximately 1.3 billion tons per year [14]. Based on Eurostat data from 2006, two different pan-European studies $[15,16]$ have estimated the amount of food waste across EU-27 to around 89 million tons per year, corresponding to $179 \mathrm{~kg}$ per capita.

All available studies consistently come to the conclusion that one of the largest savings potential in Europe is at the household level. Using various national data sources, the BCFN study [16] specifies the amount of food wasted in households per capita and year for different European countries as follows: $110 \mathrm{~kg}$ in Great Britain, $108 \mathrm{~kg}$ in Italy, $99 \mathrm{~kg}$ in France, $82 \mathrm{~kg}$ in Germany, and $72 \mathrm{~kg}$ in Sweden. These figures illustrate that any effective strategy to combat food wastage needs to focus on the final consumer.

In order to get deeper insights into consumers wasting behaviors, a survey on food waste generation in households was carried out in 2013, jointly by the European Commission's Joint Research Center in Ispra, the University of Bologna and the Karlsruhe Institute of Technology. The results of the survey will be presented in this paper. They can help to understand the reasons for discarding edible food, to identify the food groups that are wasted most and to highlight, as far as possible, any differences between Italy and Germany. In addition, the results of the survey can support the identification of measures and instruments to reduce food waste and to increase consumers' awareness on that issue. 


\section{Methodological Approaches to Quantify Food Waste at Household Level}

There are significant differences in the disposal patterns of households, which can be identified with various methodological approaches. The available studies use household surveys by means of questionnaires or interviews [8,17-21], kitchen diaries [9,18,22-26], waste composition analyses [11,26-28] and calculations based on statistical data on food supply [14,27,29] or on municipal waste $[15,16,30]$. The methods used can be roughly assigned to two groups: (1) collection, sorting and analysis by a third party; or (2) measuring and reporting by the consumers themselves [25]. Both groups of approaches have their advantages and disadvantages.

The implementation of household surveys is methodically simple, but can provide primarily qualitative information, because quantitative estimates made from memory regarding the weight of food purchased and discarded are very prone to error [12]. Experiences also teach that consumers substantially underestimate their losses when self-reporting [26,31,32]. Face to face interviews involve the risk of influencing the respondent by the presence, status and behavior of the interviewer. Responses could be influenced by participants' desire to present themselves in a positive light. Thus, a respondent may tend to give "socially accepted answers" of which he believes that the interviewer is expecting them $[17,23,33]$.

The keeping of kitchen diaries, in which the participants themselves assess their waste by sorting and weighing the individual food items disposed of, can in principle provide more robust data. However, this approach is time-consuming for the test persons and may lead, as a result of the conscious participation, to changes in the handling of foodstuff by the household members $[9,18]$. This applies even more since the topic of wasting food is associated with emotional and moral judgments [12]. Furthermore, household diaries are a quite expensive method. As a consequence, studies applying this approach are often based on very small sample sizes. The study of Gusia [22], for example, involved 39 German households in the district of Ludwigsburg; in the study of Williams et al. [23], 61 Swedish households participated; Selzer [24] investigated 30 households in Austria; and Langley et al. [25] studied 13 households in Great Britain. Extrapolations based on small sample sizes may lead to less reliable results.

Waste composition analyses, which are carried out by a third party without the knowledge and active participation of households, are considered to be a more objective and accurate method for determining the amount and structure of food thrown away by consumers. The weakness of this approach is that there is no internationally standardized collection method and no consistency of the definitions used [34]. Furthermore, unless the waste analysis is based on a daily collection, which is unlikely due to the expense and the burden for the participants, it may not give detailed information about the original features of the utilized products. Depending on the degree of decay, one can hardly distinguish whether already spoiled or still edible products were discarded; whether residues are the remains of self-cooked meals or of pre-manufactured products; and so on. Another limitation is that primarily food items that are left to municipal waste collection are covered, while other disposal paths like backyard composting, discarding via sewer and feeding to pets can hardly be traced. Finally, a waste analysis does not give any indication of the reasons and motivations of households for the disposal of food, broken down to food groups [18,25].

The advantage of calculations based on statistical data on municipal waste or on food supply is, similar to waste composition analyses, that they can be performed without the involvement of consumers. However, they are subject to many uncertainties and limitations. The waste category WO9 "animal and vegetal waste" under Eurostat, for instance, does not provide a special subsector with data on food waste. 
Waste data are submitted by the individual Member States, but there is no standardized methodology for the collection and processing of these data [15]. Furthermore, Eurostat-data do not allow for a differentiation by single food groups. In contrast to Eurostat, the food balance sheets of the FAO are differentiated according to food groups. However, the sheets only give information on food production, imports and exports, but do not take into account losses at the different stages of the food supply chain. Thus, calculations based on these data have to make assumptions on specific loss percentages for the individual stages of the food supply chain, which in turn must be taken from other studies [1]. Finally, statistical data do not enable an analysis of the reasons for the disposal of food.

Pondering the strengths and weaknesses of the individual methods, empirically elaborated studies usually apply a combination of different approaches. Van Westerhoven and Steenhuisen [11] combined an online survey on waste behavior of 1000 Dutch households with waste composition analyses of 110 households in eleven representative municipalities in the Netherlands. Watanabe [27] combined the results of a survey on food purchased and discarded in 3586 randomly selected households from 300 municipalities in Japan, with estimates based on statistical data on food supply and nutrition. The most extensive and detailed studies are published by WRAP for the UK [9,26,35]. For the WRAP study, "The Food We Waste" [26], 2715 doorstep interviews were carried out within nine local authorities in England and two local authorities in Wales. Several weeks later the waste from 2138 of the interviewed households was collected and analyzed. The combination of different methodological approaches within the same examination space is useful as the results provided by one approach can be supported - or even relativized - by the results provided by the others.

\section{Structure of the Online Survey}

The survey carried out in Ispra and Bologna on households' behavior towards food wasting was the first one of this type in Italy. In Germany, the results of similar surveys are available [17,32,36], which are, however, in some points contradictory. The intention of the new survey was to collect more recent information, including issues that have not also been covered by previous inquiries. Quantitative information on the generation of food waste in Germany - as well as in Italy - are mainly taken from calculations based on statistical data [16,29,30,37]. Against this backdrop it was a further concern of the survey to reflect the data collected by the survey against the results of calculations.

The survey was based on a questionnaire jointly prepared by the European Commission's Joint Research Centre, the University of Bologna and the Karlsruhe Institute of Technology. The socio-demographic composition of the sample was quite different at the three sites. While in Ispra and Karlsruhe the questionnaire was distributed within two scientific institutions (JRC and KIT), the survey in Bologna was opened to the general public. Thus, the socio-demographic characteristics of the respondents as well as the sample size of Bologna are hardly comparable to the other two locations. In order to carry out a meaningful and methodologically correct evaluation of the survey results, only the responses gathered in Ispra and Karlsruhe are taken into consideration for the comparison presented here.

The focus of the survey was on household behavior (shopping, eating and food preparation habits) and its influence on the generation of food waste. Furthermore, reasons and motivations for discarding food items as well as measures and technologies for the prevention of food waste were discussed. The study only covers "avoidable" food waste, which means products that are still fit for human consumption at 
the time of discarding or products that would have been edible if they had been eaten in time. "Unavoidable" food waste, which is defined as products or ingredients that are not suited to human consumption in accordance with today's food standards (e.g., vegetable peelings, bones, egg shells), was excluded. Drinks, other than milk and potable dairy products, were excluded as well. Respondents had the choice between the original English version and an Italian or German translation of the questionnaire.

It should be mentioned that the survey results of Karlsruhe and Ispra are by no means representative for the entire population of the two countries concerned. One reason is that the survey was limited to an academic environment at both locations. Due to the circle of addressees, lower income classes, households with lower education level, young people (below 18 years) and the elderly (persons aged 60 years and above) are not adequately represented in the sample. Another reason is that the questionnaire was sent via Internet to different institutes of the JRC and the KIT and it was up to the recipients to open the link or not. It can be assumed that mainly people with a distinct interest in environmental issues and sustainability were willing to spend their time answering. A third aspect that should be taken into account is that the share of Italians within the staff of the JRC is quite small, whereas the majority of employees are coming from other EU-Member States. However, although the majority of the JRC employees are not native Italians, they are living in Italy; this means that they are dependent on the local food supply and probably influenced by the Mediterranean eating culture.

\section{Results}

The results of the survey are analyzed especially with regard to two questions: (1) Are there significant differences between Ispra and Karlsruhe? (2) Are there significant deviations of our results from the results of other available studies? In the following the main findings of the survey will be introduced.

\subsection{Socio-Demographic Characteristics of the Respondents}

In Karlsruhe as well as in Ispra the number of persons who filled in the questionnaire was quite similar, with 453 respondents in Karlsruhe (55.2\% male, $43.7 \%$ female) and 404 respondents in Ispra (44.6 male, 55.4 female). It should be noted that not all respondents answered every question so that the populations are slightly different for each question.

The socio-demographic characteristics of the responding households show some differences between the two sites. In Karlsruhe more than $40 \%$ of the participating persons are 18 to 30 years old, whereas in Ispra the focus lies on the age groups 31 to 40 years (36\%) and 41 to 50 years $(29 \%)$. It should be stressed that age and sex is attributed to the person who answered the questionnaire, whereas data about shopping and consumption habits and especially about food waste generation are typical for the entire household, which, in most cases, comprises various persons of different age and sex. In both countries two person-households have the highest share (40\% in Karlsruhe, $29 \%$ in Ispra). There are only slight differences between Karlsruhe and Ispra in the share of households with three or four persons. Households with five persons are quite rare (3\% in Karlsruhe, $8 \%$ in Ispra). The number of households with six and more persons is almost negligible in both locations.

Regarding the yearly income, households in Ispra earn more money on average. The share of the highest income group (more than $€ 60,000$ ) is $30 \%$ in Ispra, while it is only $12 \%$ in Karlsruhe. The number 
of households in the income groups from less than $€ 12,000$ till $€ 48,000$ is higher in Karlsruhe (72\% in Karlsruhe, $52 \%$ in Ispra). In Ispra 97\% of the respondents are employees of the European Commission or a related organization, in Karlsruhe $84 \%$ are employees of the KIT, $11 \%$ are students. The level of education is slightly higher in Ispra, where the group of persons with a doctoral degree is larger; only two persons are students. In Karlsruhe, people with a master/diploma-degree are prevailing.

\subsection{Often Discarded Food Groups and Reasons for Wasting}

Figure 1 shows to which extent different food groups are disposed of sometimes or often (the number of answers to these two options was summed up). In general, there are no large differences between Karlsruhe and Ispra. In both locations the highest percentage (more than 40\%) of foods that are thrown away sometimes or often relates to fruit, vegetables, bread, and cheese. Relatively higher percentages in Ispra concern legumes/seeds, eggs, milk and vegetables, relatively lower percentages mainly affect bread.

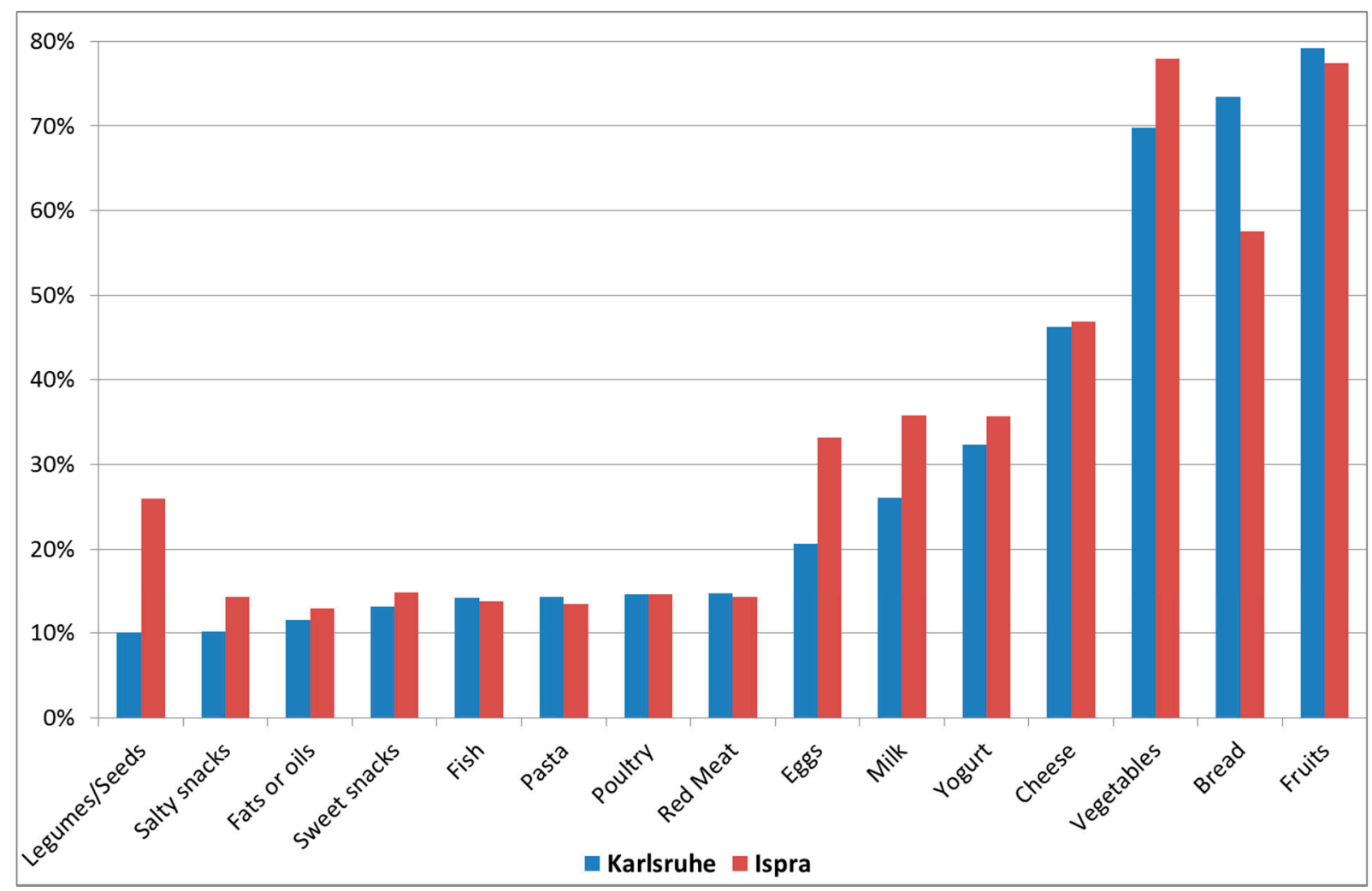

Figure 1. Food items, thrown away often or sometimes (percentage of respondents who ticked the given items).

With respect to the reasons why food is wasted, there are again no large differences between Karlsruhe and Ispra. Main reasons (For this question, multiple answers were possible) are "out of date", "in fridge too long", "smelted/tasted bad", and "mouldy" at both sites (see Figure 2). However, in Ispra "out of date" was mentioned much more frequently (57\% of respondents in Ispra compared to $32 \%$ in Karlsruhe). In contrast, "mouldy" and "smelled/tasted bad" as reasons for discarding food items were ticked much more often in Karlsruhe (78\% and 48\%, respectively) compared to Ispra (37\% and 32\%, respectively). All other reasons were mentioned less frequently (less than $25 \%$ ), which suggests that they are of minor importance. 


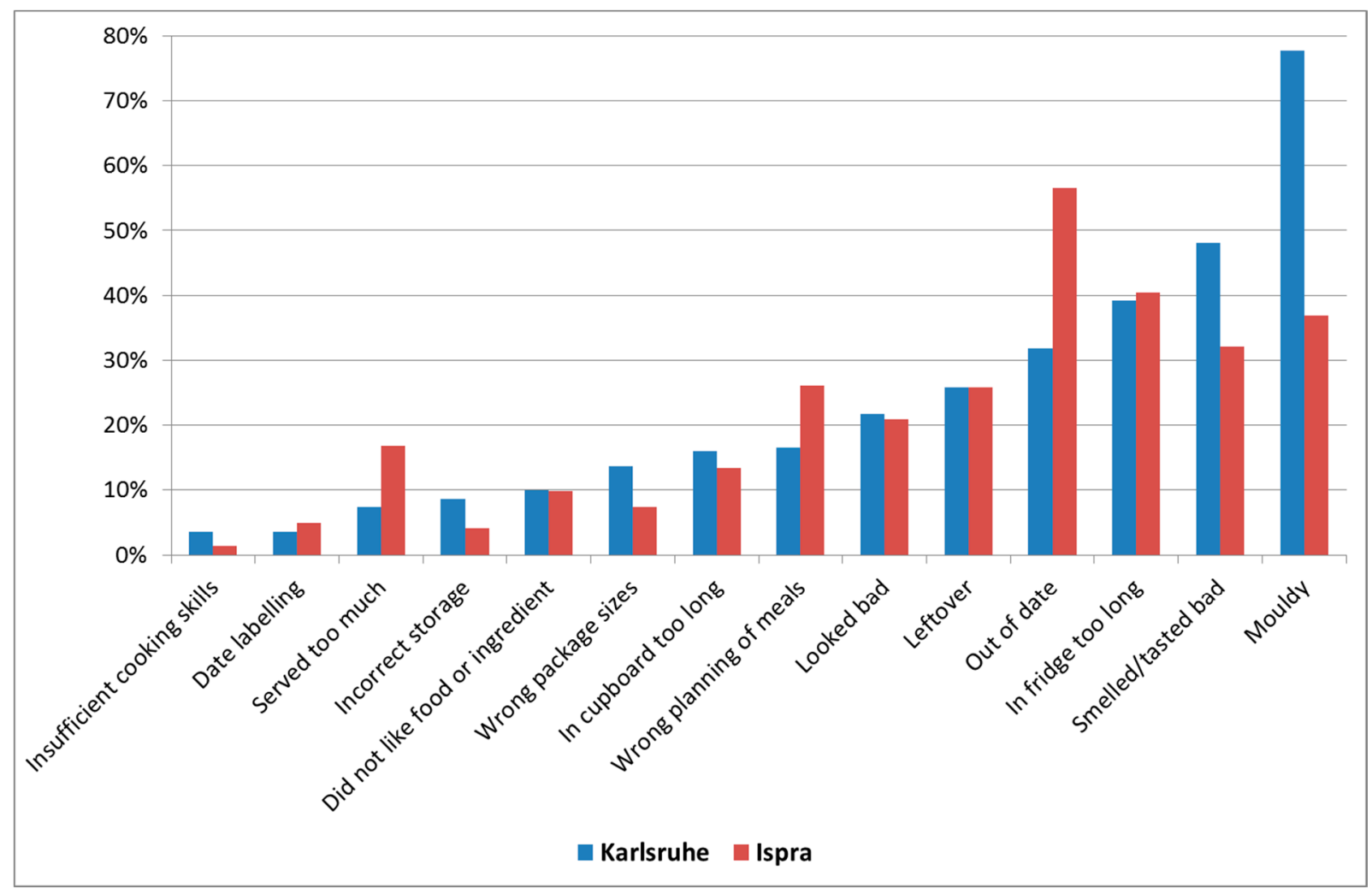

Figure 2. Reasons that lead to food being wasted (percentage of respondents who ticked the given reasons).

\subsection{Interrelations between Household's Characteristics and Food Wasting}

The respondents were asked to estimate the amount of edible food they dispose of in their households per week based on predefined categories, ranging from throwing away nothing up to more than $2 \mathrm{~kg}$ at highest (The specified categories were: nothing, less than $250 \mathrm{~g}, 250-500,500-1000,1000-2000$, and more than $2000 \mathrm{~g}$ per household/week. For the quantitative calculation, the upper limit was always used. The reason for this decision was that, following the results of many studies, consumers tend to underestimate their own contributions). On the basis of this information, the average amount of food thrown away per household and per person was calculated.

Thirty-seven percent of the respondents in Ispra (139 out of 372) and 28\% in Karlsruhe (120 out of 422) stated that they do not throw away any edible food, whereas only one household with four persons in Ispra conceded that they dispose of more than $2 \mathrm{~kg}$.

The average value of food waste is $140 \mathrm{~g}$ per person/week in Karlsruhe and $127 \mathrm{~g}$ per person/week in Ispra. A simple extrapolation of these figures to the entire population of the two countries involved results in 597,000 tons of food waste per year for Germany and 408,000 tons per year for Italy. Compared to the quantities estimated in the BIOIS study (Monier et al., 2010) of 7.7 million tons per year for Germany and 2.7 million tons per year for Italy, the amounts of food waste calculated on the basis of our survey are very small. These differences cannot be adequately explained by the fact that the figures of BIOIS also contain the non-edible parts of food items, which were excluded from the survey. Other studies based on kitchen diaries or waste composition analyses report higher waste rates as well. However, as 
can be seen from Table 1, the results vary greatly, sometimes like in the case of UK even for the same country.

Table 1. Average amount of household food waste per capita per week in different European countries.

\begin{tabular}{cllc}
\hline Food Waste in g & \multicolumn{1}{c}{ Country } & \multicolumn{1}{c}{ Source } & Reference \\
\hline 153 & Austria & Selzer (2010) & {$[24]$} \\
442 & Finland & Koivupuro et al. (2012) & {$[18]$} \\
548 & Sweden & Williams et al. (2012) & {$[23]$} \\
904 & the Netherlands & van Westerhoven (2013) & {$[38]$} \\
199 & United Kingdom & Langley et al. (2010) & {$[25]$} \\
1346 & United Kingdom & Ventour (2008) & {$[26]$} \\
1500 & Germany & Cofresco (2011) & {$[32]$} \\
\hline
\end{tabular}

The factor "household size" has a huge impact on the amount of edible food disposed of per capita. As shown in Figure 3, households with one person waste the most per capita (about $243 \mathrm{~g}$ per person/week in Karlsruhe and about $205 \mathrm{~g}$ per person/week in Ispra). The food waste rate per capita is significantly lower for households with two and more persons in both locations. In Ispra, households with more than four persons show a very low waste rate per capita. Within this group, which consisted of 32 households, 11 stated that they don't throw away any edible food and 10 stated that they throw away less than $250 \mathrm{~g}$ per week.

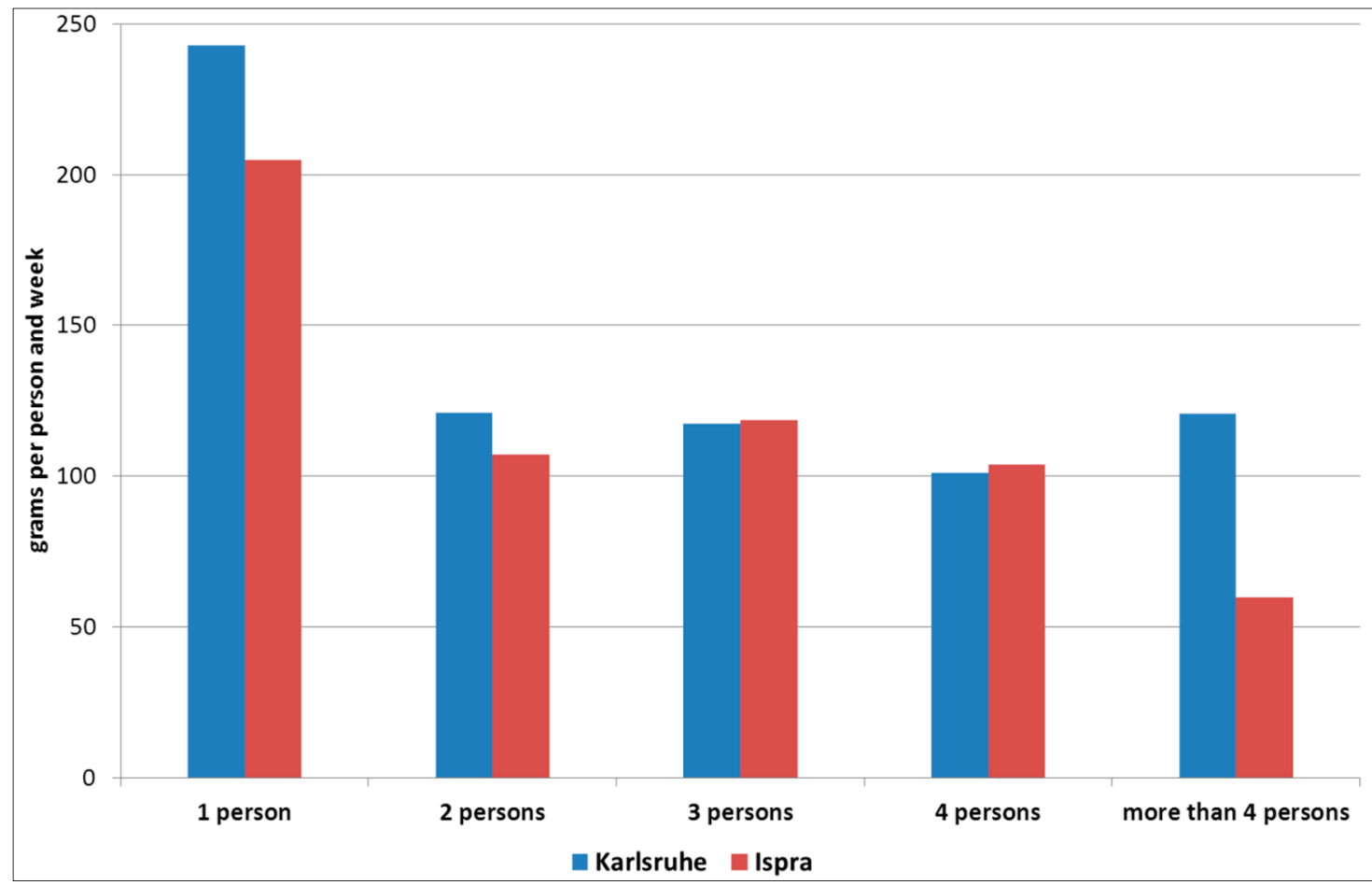

Figure 3. Per capita amount of food thrown away (grams per person/week) in relation to household size.

The amount of edible food thrown away in relation to age groups is shown in Figure 4. Again one can observe similar wasting behaviors in both locations. Until the age of 40 years there is a slight increase 
in the amount of food thrown away. In the following age groups there is a slight decrease, whereas in the category "more than 60 years" there is again a sharp increase. However, as the group of people over 60 includes only eight households in Karlsruhe and five households in Ispra, this finding is not statistically significant.

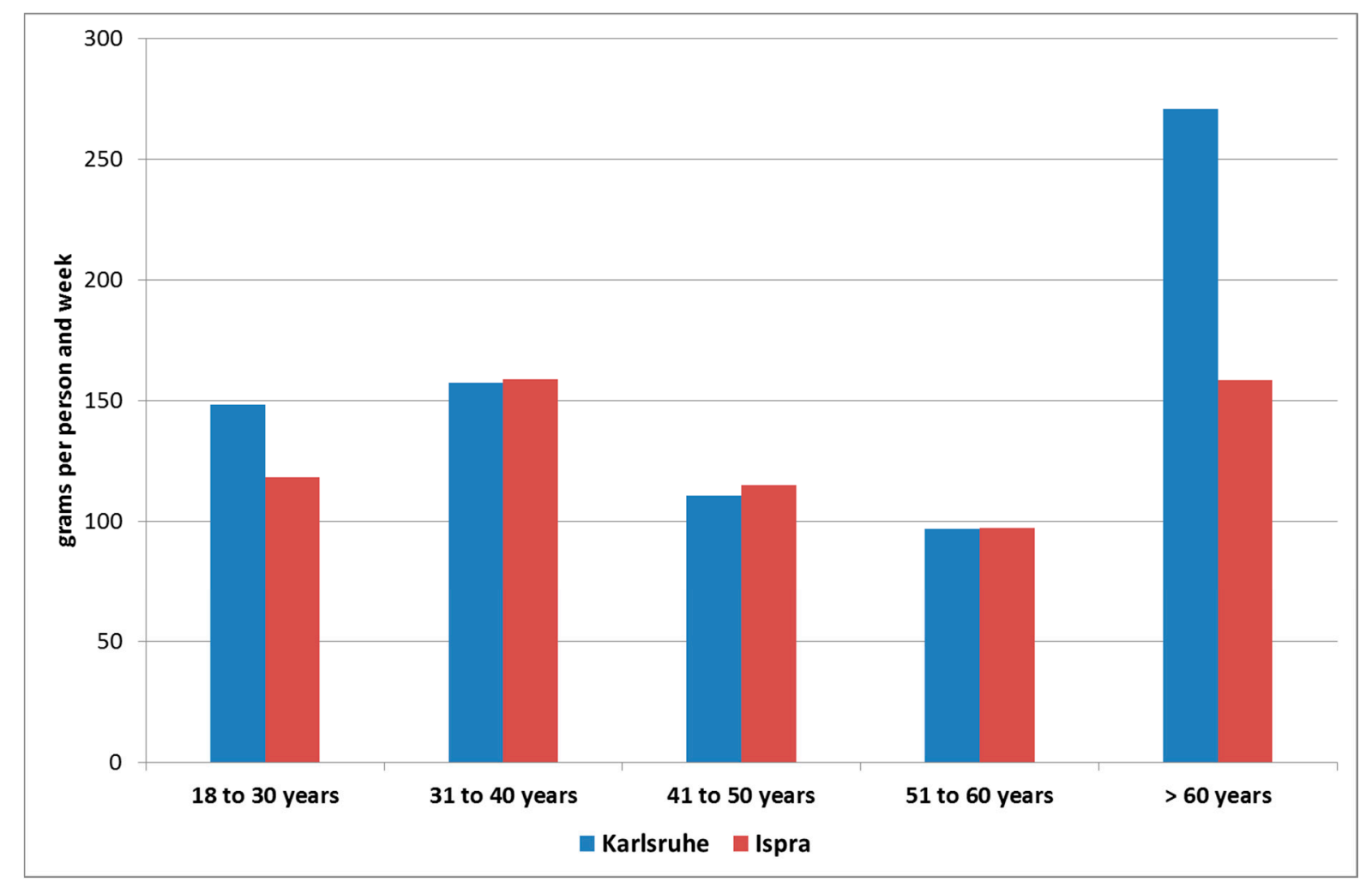

Figure 4. Per capita amount of food thrown away (grams per person/week) in relation to different age groups.

\subsection{Interrelations between Shopping Behavior and Food Wasting}

There are only small differences concerning shopping behaviors between Karlsruhe and Ispra. The most frequented stores (Multiple answers were possible for this question) to shop for groceries are large super markets (91\% in Karlsruhe, 93\% in Ispra). Forty-two percent of the respondents in Karlsruhe and $47 \%$ in Ispra reported that they exclusively shop in large supermarkets. Forty-nine percent of the respondents in Karlsruhe and 35\% in Ispra purchase food also in small shops; 25\% in Karlsruhe and $21 \%$ in Ispra visit local markets in addition to other shopping facilities. Around $13 \%$ of all respondents in Karlsruhe as well as in Ispra said that they supplementary produce their own food. Only a small number of households at both locations shop for groceries online or use home delivery (less than $2 \%$ in Karlsruhe compared to 7\% in Ispra). As shown in Figure 5, the amount of food thrown away is highest when people exclusively shop in large supermarkets, decreases when purchasing takes place in different shopping facilities, in small shops and local markets, and is lowest when people also grow their own food.

In Karlsruhe as well as in Ispra, most households purchase groceries twice a week (51\% in Karlsruhe and $44 \%$ in Ispra). Figure 6 shows the specific amount of food thrown away (grams per person/week) in relation to shopping frequency. In Karlsruhe there is a slight increase in food waste generation with decreasing shopping frequency, whereas in Ispra the opposite can be observed. 


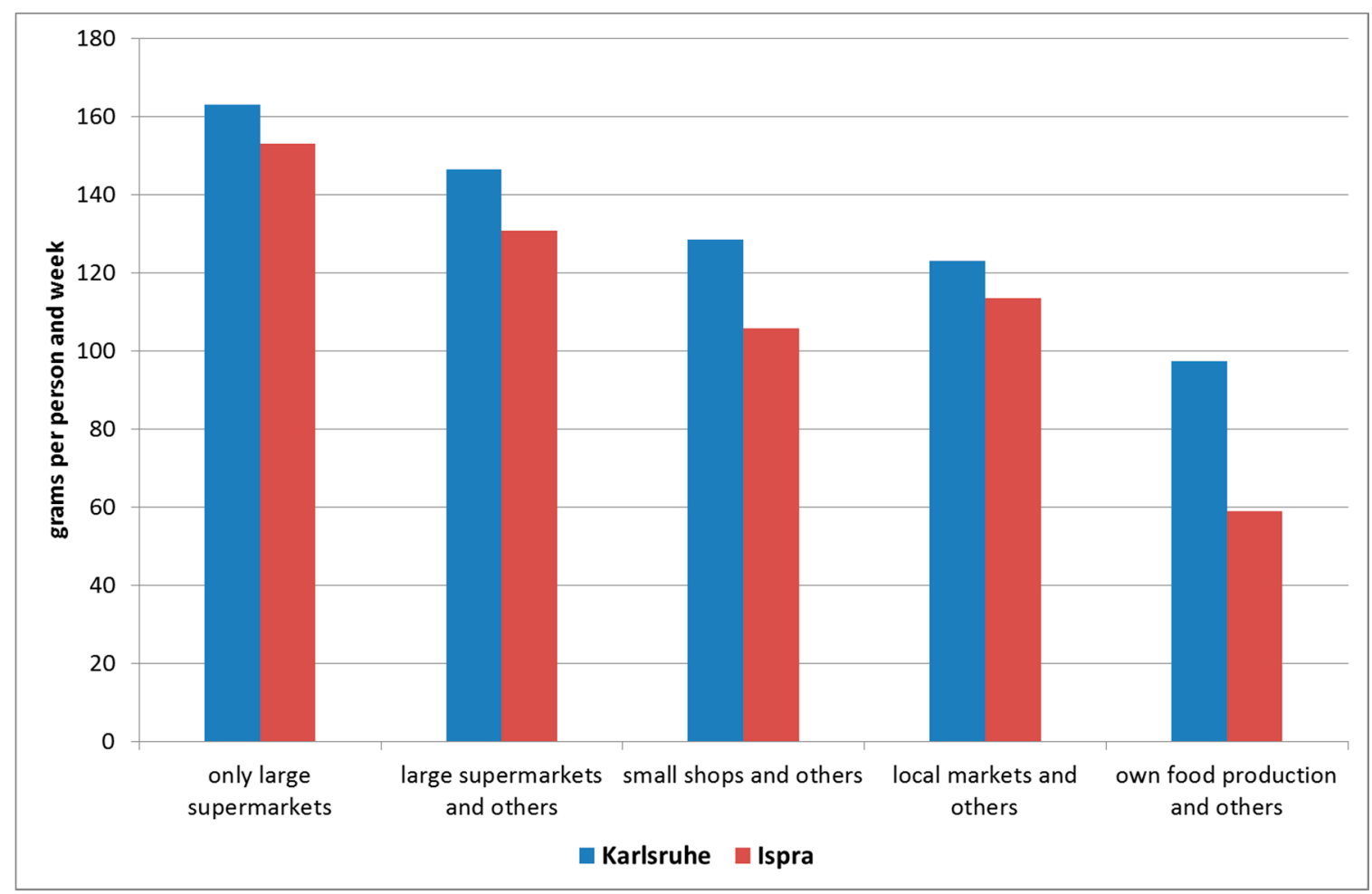

Figure 5. Per capita amount of food thrown away (grams per person/week) in relation to different shopping facilities.

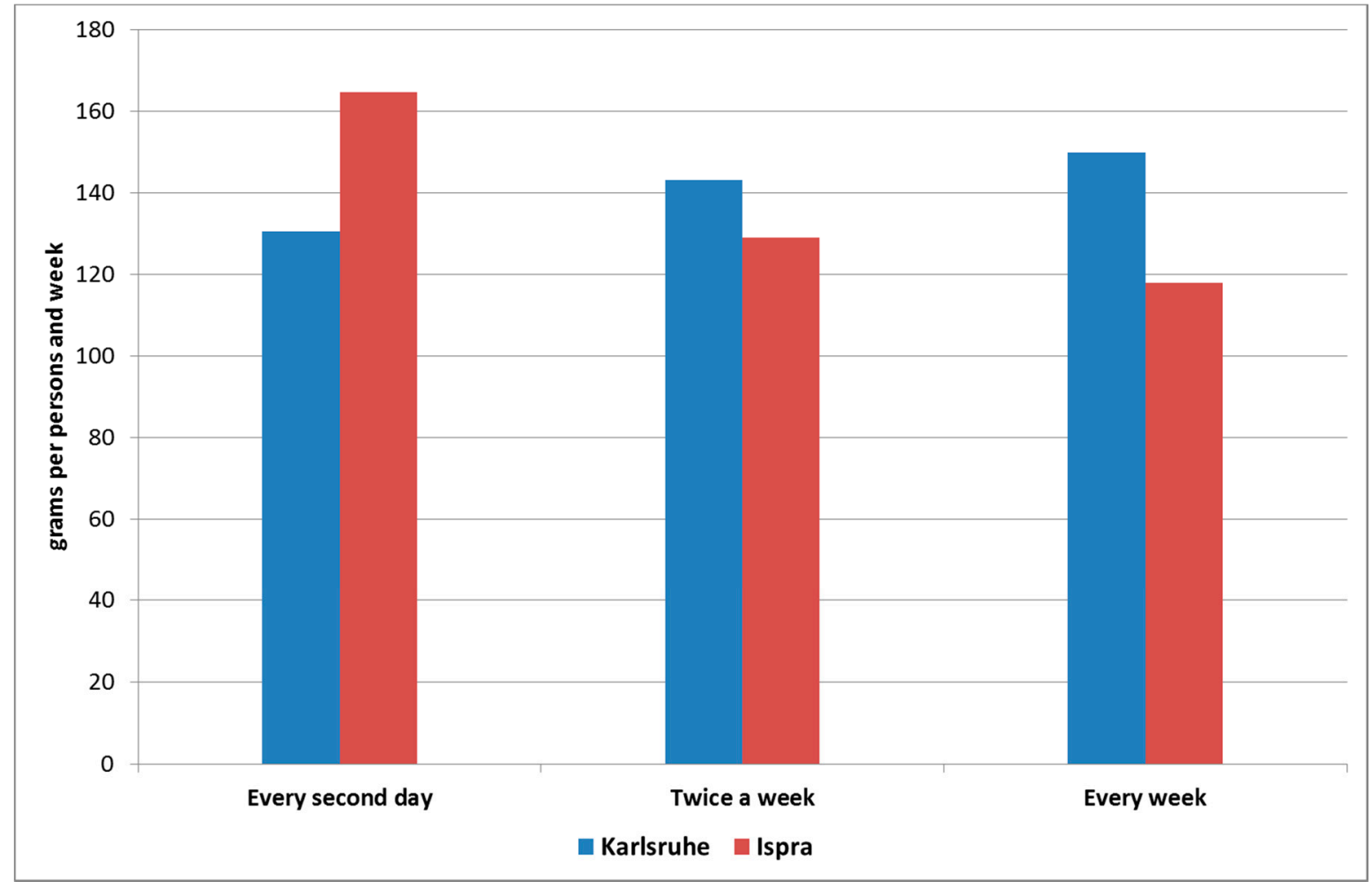

Figure 6. Per capita amount of food thrown away (grams per person/week) in relation to the frequency of shopping. 
In Karlsruhe as well as in Ispra nearly, 70\% of households use a shopping list. The amount of food waste is higher when no shopping list is used: $162 \mathrm{~g}$ in Karlsruhe compared to $131 \mathrm{~g}$ with shopping list and $157 \mathrm{~g}$ compared to $117 \mathrm{~g}$ in Ispra.

The answers to the question "Do you think you are drawn to special offers?" (e.g., "buy one get one free", "three for the price of two", etc.) can be seen from Table 2. In Ispra, households are to a larger extent attracted by special offers than in Karlsruhe.

Table 2. Share of households drawn to special offers.

\begin{tabular}{ccc}
\hline Title & Karlsruhe & Ispra \\
\hline Yes & $18.9 \%$ & $45.4 \%$ \\
Sometimes & $55.4 \%$ & $37.8 \%$ \\
No & $25.7 \%$ & $16.9 \%$ \\
\hline
\end{tabular}

Figure 7 indicates that the amount of food waste is slightly lower in households that tend to buy discounted groceries than in households that are not interested in special offers.

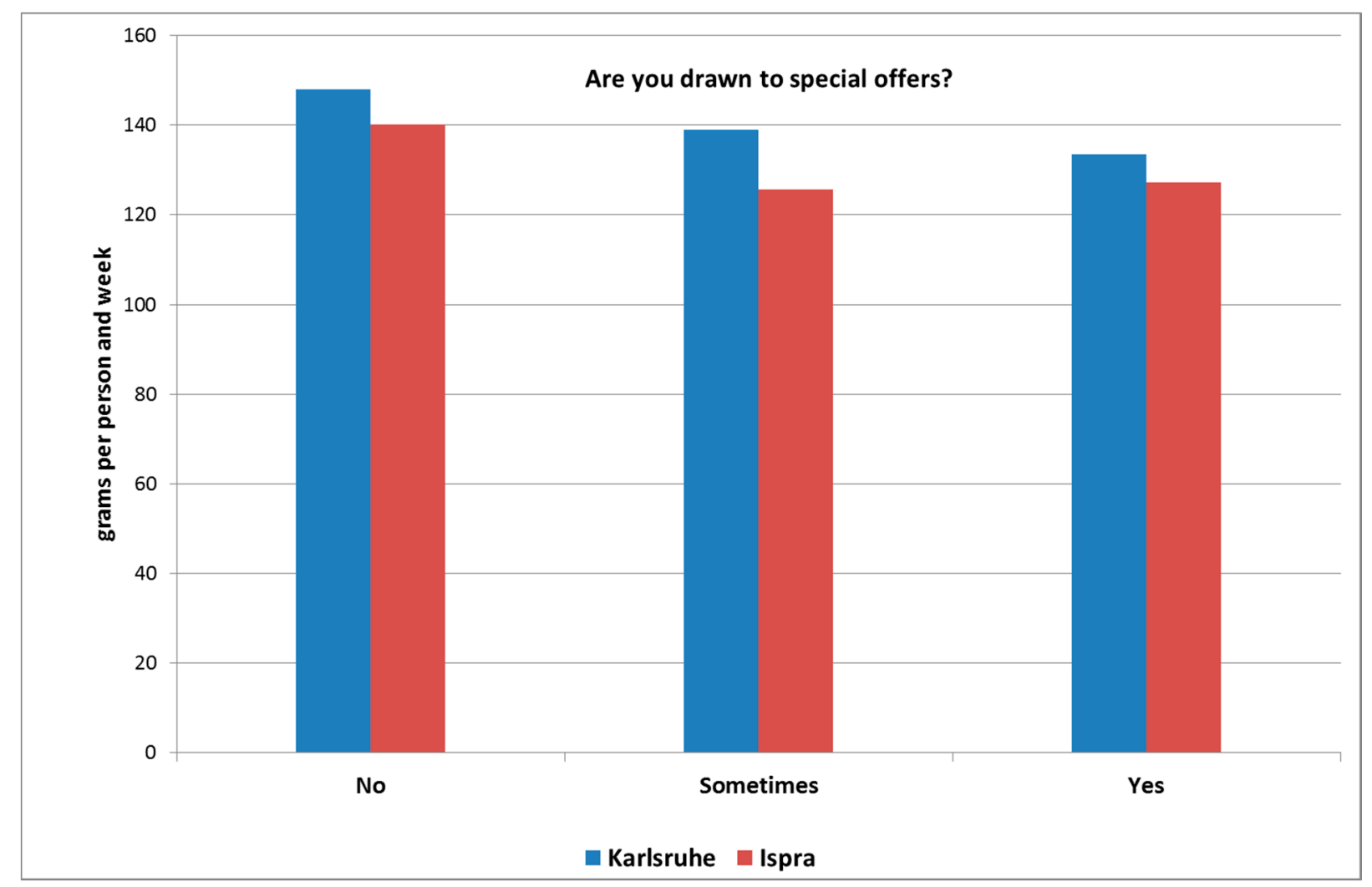

Figure 7. Per capita amount of food thrown away (grams per person/week) in relation to the interest in special offers.

\subsection{Evaluation of Prevention Measures}

The majority of respondents indicated that they already strive towards reducing food waste (70\% in Karlsruhe, $82 \%$ in Ispra). The most mentioned activities referred to organizational improvements, like optimized planning of meals according to needs, tailored food purchases, consumption of perishable food items in time, adequate storage and reuse of leftovers. Although there are many efforts to improve 
organizational processes at home, this field was still identified as a weak point by many respondents. Mainly temporal constraints due to high workload resulting in a lack of time for family management were often cited as reasons for the generation of food waste. Households with children specified that food is wasted due to behaviors and preferences of kids and teenagers, which should be an important target group for prevention activities. The need of an early childhood education on the issue of food waste was frequently emphasized.

Regarding the question of what kind of measures would be necessary to further reduce food waste at consumer level, smaller packaging sizes was selected the most, followed by portion sizes in restaurants and canteens that meet one's need. The issue of packaging sizes was underpinned by additional comments, which stressed that the packaging sizes for some produce like carrots, tangerines, bananas; dairy products like milk, cream, cheese; and eggs, but also baking ingredients, packaged sausages and meat products as well as fresh pasta and pizza (the latter especially in Ispra) are too big and prices for smaller units and not pre-packed foods are comparatively high.

The effectiveness of economic incentives, such as raising the value-added tax rates for the prevention of food waste were estimated to be low, both in Karlsruhe and Ispra. In contrast to Karlsruhe, respondents at Ispra also assumed that making monetary losses visible would have little impacts. This may be linked to higher incomes at the JRC in Ispra. Waste fees that are charged according to the generated amount of food waste were expected to be quite effective in Ispra, whereas not in Karlsruhe. This difference can be explained by the fact that waste fees depending on quantity or volume are not yet widespread in Italy, while they are common practice in Germany.

Information that would be needed to reduce food waste by households is primarily knowledge on the freshness and durability of a product. With similar significance, advice is required about how to share or donate food, how to store food correctly and recipes for how to use leftovers. Respondents in Karlsruhe as well as in Ispra would like to receive further information with first priority via e-mail, whereas in Germany a preference for postal delivery was apparent. Further ideas for the distribution of information are related to the products themselves, supermarkets, and websites of local authorities. A considerable share of respondents does not need or wish any further tips due to a prevailing information overload.

The survey also covered the question, to which extent technologies can help to reduce food waste. The following technologies were included in the questionnaire (it was possible to choose more than one technology): Extending shelf life of products, smart packaging (Packaging with color-changing indicators that warn when food is spoiling/spoilt), smart fridges/cupboards (Fridges/cupboards that offer the possibility of scanning products and inform about what is at home and when the best before dates expire), smart shopping trolleys (Shopping trolleys that make grocery shopping more efficient by planning the way through the supermarket according to a shopping list) and smart interactive tools (Online shopping websites or smartphone applications that provide information on previous purchases, expiry dates, etc.). At both locations, nearly $40 \%$ of the respondents refused to answer this question, arguing that such technologies would not contribute to the reduction of food waste. Among those who answered the question - 282 persons in Karlsruhe (62\%) and 270 persons in Ispra (67\%) - the most preferred technologies were smart packaging followed by smart fridges/cupboards and extending shelf life of products. Smart shopping trolleys and smart interactive tools met with no great interest. 


\section{Discussion}

As mentioned above, the population of the survey presented here is not representative for the two countries concerned. The main reason is that the survey was limited to an academic environment at both locations. Moreover, the questionnaire was distributed via the Internet and the response to it was completely voluntary. Due to the method used and the circle of addressees, lower income classes, households with a lower educational level, young people (below 18 years) and the elderly (persons aged 60 years and above) were not adequately represented in the sample. Thus, the results cannot be reliably extrapolated to the entire population of Italy or Germany. Nevertheless, they provide some interesting insights into households' behaviors in comparison with the findings of other studies (for the main results see Box 1).

Box 1. Key findings of the survey on food waste generation at household level.

Results that are supported by literature:

Scale of food waste generation: Households in general tend to underestimate their food waste when asked to provide information from memory.

$>$ Household size: Smaller households ordinarily produce less waste than larger households, but the amount of food waste generated per person decreases with increasing household size. Single households are wasting the most on a per capita basis.

$>$ Types of food: The largest contributors to food waste are easily perishable items like fresh fruit and vegetables, followed by bakery products, dairy products and eggs.

$>$ Reasons: The most common reasons that lead to food wastage are: out of date; looked, smelled, tasted bad or moldy; in fridge or cupboard too long.

$>$ Drivers: The most mentioned drivers for food waste are: too large packaging (mainly for small households), poor quality of purchased groceries, cooking too much due to a lack of experience, likes and dislikes of children and lack of time for family management as a result of work overload.

$>$ Source of groceries: The amount of food thrown away is highest when people exclusively shop in large supermarkets, decreases when purchasing takes place in different shopping facilities and is lowest when people also grow their own food.

$>$ Shopping organization: When using a shopping list, the amount of food thrown away per capita is lower.

$>$ Prevention measures: The most required prevention measures are organizational improvements like optimized planning of meals, tailored food purchases, adequate storage and reuse of leftovers. Early childhood education on the appropriate handling of food is also seen as an important lever.

Issues on which neither literature nor our survey provides a clear picture:

$>$ Age of consumers: Especially for the group aged over 65, many studies come to the conclusion that they waste significantly less food than the rest of the population, others argue that retired households waste the most per capita. The second observation seems to be confirmed by the results of our survey, however as these groups include only 13 households, this finding is not statistically significant.

$>$ Shopping frequency: Regarding the impact of shopping frequency on the amount of food waste, the study reveals contradictory results: a slight increase in food waste with decreasing shopping frequency in Karlsruhe and the opposite trend in Ispra. Plausible explanations can be found for both trends in the literature.

$>$ Attraction to special offers: The survey indicates that people who are more often drawn to special offers waste less food on average than people who are not interested in special offers. This is explained by the fact that people tending to buy discounted products have a higher regard for food because they cannot afford to waste money. This finding is backed by several studies, but there is also some empirical evidence for the opposite result in literature: Households which are attracted by special offers make more food waste because they are encouraged by retailers to buy more than they actually need. 


\subsection{Amount of Food Waste}

The generation of food waste per capita per week specified in the survey is $127 \mathrm{~g}$ in Ispra and $140 \mathrm{~g}$ in Karlsruhe, far below the level found in other studies. The available calculations, based on statistical data, estimate the average amount of food waste for Germany at about $1500 \mathrm{~g}$ per capita per week [15,30,32] and for Italy between 884 [15] and more than $2000 \mathrm{~g}$ per capita per week [16]. One reason for the low waste rates in our survey might be that the predefined choices for food waste generation offered in the questionnaire were scheduled too low. This may have misled respondents to specify their real waste rates at the lowest limit. Another reason could be that households in general tend to underestimate their food waste arising, when asked to provide information from memory. Ventour [26] reports that households testifying in the interview that they throw away nothing actually generated $88 \mathrm{~kg}$ of avoidable food waste a year. A third reason could be that the survey was restricted to an academic milieu. It is typical for the questioned scientists that they frequently travel on business and eat out of home. The food waste generated by the respondents out of home in hotels, restaurants, canteens, take away, coffee shops, etc. was not subject of the survey. Moreover, it is likely that people who have completed the questionnaire were mostly already sensitized to the issue of food wasting or are at least more aware of the problem than other people. This assumption is backed up by the fact that more than $70 \%$ of the respondents in both locations stated that they care very much about food waste and try to avoid it whenever possible. Also Williams et al. [23] observed that those participants who have a high environmental consciousness waste less food.

\subsection{Type of Foods Going to Waste and Reasons for Discarding}

Concerning the food items wasted most the results of the survey are in line with the findings of previous research. Most studies indicate that the largest contributors to food waste are easily perishable items like fresh fruit and vegetables, followed by bakery, dairy products and eggs [8,9,25,26,30]. This sequence of most discarded foods applies also for Karlsruhe and Ispra.

As can be seen from figure 1 there is only one striking difference between the German and the Italian location: The percentage of legumes and seeds disposed of at Ispra is more than twice as high as in Karlsruhe. The extent to which this difference relates to various dietary habits can certainly not be discerned from these data alone. However, it is possible that there exists a connection between wasting and consumption patterns. Although the staff members of the JRC in Ispra mostly come from other EU-Member States, it is not unlikely that their eating habits are influenced by the local food supply and the Mediterranean culinary culture. Large-scale studies in the late 1990s, based on FAO's food balance sheets and information from the European "Data Food Networking" (DAFNE), revealed that the major differences in dietary patterns between Mediterranean and the Central/Northern countries identified in the 1960s have leveled out [39-42]. Considerable disparities remain with regard to the consumption of legumes and seeds, which are still characteristic for the Mediterranean diet and seem to be, together with olive oil, the only food items that show a clear North/South gradient.

Several studies investigated the reasons for the generation of food waste $[9,17-19,21,26,33]$ and have come to quite similar results. Looking at the findings of our survey with respect to previous research, the most common reasons that lead to food wastage are: 
- Out of date

- Looked, smelled, tasted bad/moldy

- In fridge/cupboard too long

- Wrong planning of meals, not need-based shopping, wrong packaging size

- Insufficient cooking skills, incorrect storage

- Served too much, leftovers, did not like ingredients.

Comparing the answers to this question (see Figure 2), one interesting difference can be observed between both locations: The most commonly cited reason to discard food in Ispra was "out of date" (57\%), whereas the most cited reason in Karlsruhe was "mouldy" (78\%) followed by "smelled/tasted bad" (48\%). This indicates that respondents in Ispra seem to rely more on producers' instructions, whereas respondents in Karlsruhe seem to trust more in their sensory perception. A possible explanation for this difference might be that the awareness campaign launched in 2012 by the German Federal Ministry of Food, Agriculture and Consumer Protection is already showing effects. This campaign, which was widely reported in newspapers, websites and television debates, pursued among others the goal to inform consumers on the true meaning of food labeling and the difference between the "best before" and the "use by" date.

Within the questionnaire, there was no differentiation made between "reasons" and "drivers" of food wasting. The immediate reason to discard a food item may be that it is out of date or moldy, but the factors that trigger food to become out of date or moldy are, e.g., buying too much, inadequate storage, not eating the food that need to be eaten first or dissatisfaction with the taste of food [21]. The analysis of the answers to the open questions in the survey reveals that the most mentioned drivers for food waste were in our case: too large packaging mainly for small households, poor quality of purchased groceries, cooking too much due to a lack of experience, likes and dislikes of children and lack of time for family management as a result of work overload.

\subsection{Socio-Demographical Factors}

Most of the available studies have shown a strong correlation between the amount of food waste and household size. The absolute amount of food waste strongly depends on the number of persons per household, so that smaller households ordinarily produce less waste than larger households, but the amount of food waste generated per person decreases with increasing household size. Single households are wasting the most on a per capita basis $[18,24,26,43]$. This finding of previous research is supported by the results of our survey. As can be seen from Figure 3 people in four-person households generate less than half the amount of food waste per capita compared to single-households. This observation can be understood considering that there are some factors that make efficient supplying of smaller households more challenging: food is often only available (or cheaper) in big packages, recipes usually cater to groups rather than to individuals and more variability in food consumption has a greater impact in smaller households (similar [43]).

Regarding the correlation between food waste generation and age, there is no consensus in the relevant literature. Many studies come to the conclusion that the over $65 \mathrm{~s}$ waste significantly less food than the rest of the population $[18,19,21,24,43,44]$. To explain this phenomenon, it is argued that people over 65 are influenced by rather different experiences. This includes austerity and food shortage during the 
Second World War as well as an education on the careful handling of food based on the fact that the share of household income spent on groceries was much higher in those times than today. In contrast to the popular opinion, Ventour [26] reports that the majority of singles, who waste the most on a per capita basis, is at retirement age. The observation of Ventour seems to be confirmed by the results of our survey (see Figure 4). However, as the group of people over 60 includes only eight households in Karlsruhe and five households in Ispra, this finding is not statistically significant. Nevertheless, there are good arguments, which support Ventour's observation: Retired households are usually small households of which we know that they waste the most per capita. The immediate post-war generation that was educated to a high respect for food and has experienced austerity and food rationing is slowly dying out. Many elderly today are already socialized differently and have experienced prosperity and abundance; so one can assume that their appreciation for food is rather low. It is also likely that they continue to retain the same attitudes and behaviors to food that they had all their lives in the age of retirement (similar [45]).

\subsection{Shopping Habits}

In accordance with previous studies, the survey endorses the finding that households' shopping practices have a huge impact on the level of food wasting. The most frequented stores for purchasing groceries in Ispra as well as in Karlsruhe are large supermarkets. As shown in Figure 5, the amount of food thrown away is highest when people exclusively shop in large supermarkets, decreases when purchasing takes place in different shopping facilities, and is lowest when people also grow their own food. An explanation for this result could be that people who spent a lot of time shopping in small shops or local markets attribute a higher value to foods than people who prefer the quick and convenient large supermarkets. This applies even more for people who cultivate their own food and have experienced the restrictions, imponderables and seasonal limits of agricultural production.

Next to the type of shopping facility chosen, the shopping frequency also affects the amount of food waste. Here the survey shows contrary trends: in Karlsruhe there is a slight increase in food waste with decreasing shopping frequency, whereas in Ispra the opposite can be observed. The result for Karlsruhe-less food waste in households that purchase groceries more often - ties in with the findings of Williams et al. [23] and Glanz [19]. One explanation given is that more frequent shopping allows for a better matching with the daily needs. The purchase of large quantities for the whole week in contrast, would increase the probability of spoilage, especially of perishable products, such as vegetables, bread and milk. Another rather psychological foundation is provided by Graham-Rowe et al. [33]. The authors found that the habit of some people to buy foodstuff, in bulk or even in excess of their needs, is linked to the desire to minimize inconveniences and to avoid untimely trips to the shops. Stocking up on food is seen as a means of reducing future stress and freeing up time for other responsibilities or personal pursuits. To this end, the disposal of unused food is tolerated.

However, there is also empirical evidence supporting the opposite trend: more food waste in households that purchase groceries more often. According to Lyndhurst et al. [21], any gains made by a better day-to-day management of food as a result of more frequent shopping might be outweighed by the risk of "spontaneous buying". Graham-Rowe et al. [33] suggest that the wish to be a "good provider" (good partner, good parent, good host) in terms of providing always fresh products and/or an ample choice of foods may trigger repeatedly over-purchasing and thus, increase the amount of food going to waste. 
As reported in different studies [19,21,32,33], consumers see the responsibility for the generation of food waste rather with supermarkets and retailers than with the individual household. Marketing strategies like "Buy One, Get One Free" (BOGOF) or the offer of discounted products would encourage consumers to buy more than they actually need and, thus, promote the wasting of food. However, this hypothesis is not undisputed. A study of Koivupuro et al. [18] in Finland provides evidence that the amount of food waste is larger in households where BOGOF and discounted products are not often bought. The authors assume that people tending to buy discounted groceries have a higher regard for food because they cannot afford to waste money on food. Similarly, Williams et al. [23] observed that households that consider prices to be an important factor, waste less food than households that state that prices do not play a crucial role. The findings of Koivupuro and Williams are supported by the results of our survey. People who are more often drawn to special offers waste less food on average than people who are not interested in special offers (see Figure 7).

In Karlsruhe as well as in Ispra, 70\% of the households surveyed use a shopping list. When using a shopping list, the amount of food thrown away per capita is lower by about $20 \%$ in Karlsruhe and $25 \%$ in Ispra. This result is also consistent with the findings of previous studies [21,24,32]. Quested et al. [43] found that there is a strong positive correlation between making a shopping list and other "planning behaviours", like planning meals in advance and checking food stocks prior to shopping. According to Quested et al., these "planning behaviours" also correlate positively with other behaviors that can contribute to reduce food waste, like using the freezer to extend shelf life of food and reusing of leftovers.

All in all, there are - apart from few exceptions - no major differences in the answers between Italy and Germany. This result strongly suggests that the attitudes towards the handling of and the regard for food are more influenced by social class and educational level than by nationality.

\section{Conclusions}

The available studies show that there are great discrepancies between the amount of food waste calculated on the basis of statistical data on food supply or municipal waste and the amount of food waste measured in household surveys. The results of statistical estimates are in general a factor of three to ten higher than the results of household surveys. This observation indicates that great efforts are required to improve the methods for statistical data collection and processing and to harmonize the definition of the term "food waste". Concerning the data provided by Eurostat, the standardization of data recording in Europe is one focus of the ongoing European FUSIONS project [46].

Regarding the collection of data by household surveys there are at least two barriers that are difficult to remove. All approaches that require an active participation of consumers, irrespective of whether people are asked to give an interview, to fill a questionnaire or to keep a kitchen diary, have the disadvantage that responses may be influenced by the participants' desire to present themselves in a positive light. A further weakness is that the test persons must give their consent. It is likely that the willingness to participate in such research will be found rather in academic or university milieus than in educationally and socially disadvantaged groups. Furthermore, online surveys, which are a cheap and very common survey method, do not reach people without the appropriate technical equipment and the relevant skills to use it. For these reasons lower income classes, households with lower education level, 
and the elderly (persons aged 65 years and above) are not adequately represented in many studies. Further considerations are much needed how to overcome these barriers.

\section{Acknowledgments}

The authors would like to acknowledge Sandra Caldeira from the European Commission's Joint Research Centre (DG-JRC), Institute for Health and Consumer Protection and Silvia Gaiani from the University of Bologna, Department of Agricultural Economics and Engineering for their initiative to launch the survey and their essential contribution to its design and realization.

We acknowledge support by Deutsche Forschungsgemeinschaft and Open Access Publishing Fund of Karlsruhe Institute of Technology.

\section{Author Contributions}

All authors participated in the design of the survey, its realization and the analysis of the results, in the literature review and in the writing of the manuscript. All authors read and approved the final manuscript.

\section{Conflicts of Interest}

The authors declare no conflict of interest.

\section{References}

1. HLPE. Food Losses and Waste in the Context of Sustainable Food Systems; The High Level Panel of Experts on Food Security and Nutrition: Rome, Italy, 2014.

2. Bio Intelligence Service (BIOIS). Modelling of Milestones for Achieving Resource Efficiency, Turning Milestones into Quantified Objectives: Food Waste. Prepared for the European Commission, DG Environment; BIOIS: Paris, France, 2013.

3. IMechE. Global Food: Waste Not, Want Not; Institution of Mechanical Engineers: London, UK, 2013.

4. Grethe, H.; Dembélé, A.; Duman, N. How to Feed the World's Growing Billions. Understanding FAO World Food Projections and Their Implications; Heinrich Böll Stiftung und WWF Deutschland: Berlin, Germany, 2011.

5. The Government Office of Science. Foresight: The Future of Food and Farming. Final Project Report; The Government Office of Science: London, UK, 2011.

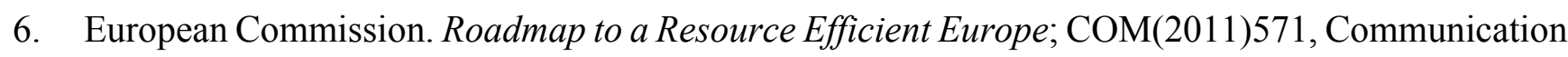
from the Commission to the European Parliament, the Council, the European Economic and Social Committee and the Committee of the Regions; European Commission: Brüssel, Belgium, 2011.

7. European Commission. Review of Waste Policy and Legislation. Available online: http://ec.europa.eu/environment/waste/target_review.htm (accessed on 16 January 2015).

8. Pekcan, G.; Köksal, E.; Kücükerdönmez, Ö.; Özel, H. Household Food Wastage in Turkey; Working Paper Series, No ESS/ESSA/006e; Food and Agriculture Organisation of the United Nations, Statistics Division: Rome, Italy, 2006. 
9. Quested, T.; Marsh, E.; Stunell, D.; Parry, A.D. Spaghetti soup: The complex world of food waste behaviours. Resour. Conserv. Recy. 2013, 79, 43-51.

10. Syversen, F.; Marthinsen, J. Matavfall fra Husholdninger i Norge-Hva Oppstår og Hvordan Håndteres det; EMMA-prosjektet: Oslo, Norway, 2010. (In German)

11. Van Westerhoven, M.; Steenhuisen, F. Bepaling Voedselverliezen bij Huishoudens en Bedrijfscatering in Nederland; CREM BV: Amsterdam, The Netherlands, 2010.

12. Schneider, F. Lebensmittel im Abfall-Mehr als eine technische Herausforderung. In Ländlicher Raum, Online-Fachzeitschrift des Bundesministeriums für Land-und Forstwirtschaft, Umwelt und Wasserwirtschaft, Jahrgang 2008; Bundesministerium für Land- und Forstwirtschaft, Umwelt und Wasserwirtschaft: Vienna, Austria, 2008. (In German)

13. Buzby, J.C.; Hyman, J. Total and per capita value of food loss in the United States. Food Policy 2012, 37, 561-570.

14. Gustavsson, J.; Cederberg, C.; Sonesson, U. Global Food Losses and Food Waste. Extent, Causes and Prevention; Food and Agriculture Organization of the United Nations (FAO): Rome, Italy, 2011.

15. Monier, V.; Mudgal, S.; Escalon, V.; O’Connor, C.; Gibon, T.; Anderson, G.; Montoux, H.; Reisinger, H.; Dolley, P.; Ogilvie, S.; et al. Final Report_Preparatory Study on Food Waste across EU 27; European Commission [DG ENV-Directorate C]; BIO Intelligence Service: Paris, France, 2010.

16. BCFN. Food Waste: Causes, Impacts and Proposals; Barilla Center for Food and Nutrition: Parma, Italy, 2012.

17. Göbel, C.; Teitscheid, P.; Ritter, G.; Blumenthal, A.; Friedrich, S.; Frick, T.; Grotstollen, L.; Möllenbeck, C.; Rottstegge, L.; Pfeiffer, C.; et al. Verringerung von Lebensmittelabfällen-Identifikation von Ursachen und Handlungsoptionen in Nordrhein-Westfalen. Studie für den Runden Tisch Neue Wertschätzung von Lebensmitteln des Ministeriums für Klimaschutz, Umwelt, Landwirtschaft, Natur und Verbraucherschutz des Landes Nordrhein-Westfalen; University of Applied Sciences: Münster, Germany, 2012. (In German)

18. Koivupuro, H.K.; Hartikainen, H.; Silvennoinen, K.; Katajajuuri, J.H.; Heikintalo, N.; Reinikainen, A.; Jalkanen, L. Influence of socio-demographical, behavioural and attitudinal factors on the amount of avoidable food waste generated in Finnish households. Int. J. Consum. Stud. 2012, 36, 183-191.

19. Glanz, R. Causes of Food Waste Generation in Households-An Empirical Analysis. Master's Thesis, University of Natural Resources and Applied Life Sciences, Vienna and Cranfield University, Vienna, Austria, 2008.

20. Schneider, F.; Lebersorger, S. Untersuchung der Lebensmittel im Restmüll in einer Oberösterreichischen Region; Universität für Bodenkultur: Wien, Österreich, 2009.

21. Lyndhurst, B.; Cox, J.; Downing, P. Food Behaviour Consumer Research: Quantitative Phase; Waste \& Resources Action Programme (WRAP): Banbury, UK, 2007.

22. Gusia, D. Lebensmittelabfälle in Musterhaushalten im Landkreis Ludwigsburg. Ursachen-Einflussfaktoren-Vermeidungsstrategien. Diplomarbeit für den Studiengang Umweltschutztechnik; Universität Stuttgart: Württemberg, Germany, 2012. (In German)

23. Williams, H.; Wikström, F.; Otterbring, T.; Löfgren, M.; Gustafsson, A. Reasons for household food waste with special attention to packaging. J. Clean Prod. 2012, 24, 141-148. 
24. Selzer, M. Die Entsorgung von Lebensmitteln in Haushalten: Ursachen-Flüsse-Zusammenhänge. Diplomarbeit zur Erlangung des Akademischen Grades Diplomingenieurin; Universität für Bodenkultur Department für Wasser; Atmosphäre und Umwelt Institut für Abfallwirtschaft: Wien, Österreich, 2010. (In German)

25. Langley, J.; Yoxall, A.; Heppell, G.; Rodriguez, E.M.; Bradbury, S.; Lewis, R.; Luxmoore, J.; Hodzic, A.; Rowson, J. Food for Thought? A UK pilot study testing a methodology for compositional domestic food waste analysis. Waste Manag. Res. 2010, 28, 220-227.

26. Ventour, L. Food Waste Report-The Food We Waste; Waste \& Resources Action Programme (WRAP): Banbury, UK, 2008.

27. Watanabe, K. Estimations of quantities of wasted food. In Proceedings of the Prosperity Waste and Waste Resources. 3rd BOKU Waste Conference 2009, Vienna, Austria, 15-17 April 2009; Lecherm, P., Ed.; Facultas. Wuv: Vienna, Austria, 2009; pp. 77-84.

28. Schneider, F.; Obersteiner, G. Food waste in residual waste of households- regional and socio-economic differences. In Proceedings of the Eleventh International Waste Management and Landfill Symposium, St. Margherita di Pula, Sardinia, Italy, 1-5 October 2007; Cossu, R., Diaz, L.F., Stegmann, R., Eds.; pp. 469-470.

29. Bräutigam, K.-R.; Jörissen, J.; Priefer, C. The extent of food waste generation across EU-27: Different calculation methods and the reliability of their results. Waste Manag. Res. 2014, 32, 683-694.

30. Kranert, M.; Hafner, G.; Barabosz, J.; Schneider, F.; Lebersorger, S.; Scherhaufer, S.; Schuller, H.; Leverenz, D. Ermittlung der Weggeworfenen Lebensmittelmengen und Vorschläge zur Verminderung der Wegwerfrate bei Lebensmitteln in Deutschland. Kurzfassung. Institut für Siedlungswasserbau, Wassergüte- und Abfallwirtschaft (ISWA); Universität Stuttgart: Württemberg, Germany, 2012. (In German)

31. Beretta, C.; Stoessel, F.; Baier, U.; Hellweg, S. Quantifying food losses and the potential for reduction in Switzerland. Waste Manag. 2013, 33, 764-773.

32. Cofresco Frischhalteprodukte Europa. Save Food Studie. Das Wegwerfen von Lebensmitteln-Einstellungen und Verhaltensmuster. Quantitative Studie in Deutschen Privathaushalten. Available online: http://www.cofresco.de/pdf/Results_Save_Food_Study_ Germany.pdf (accessed on 12 January 2015). (In German)

33. Graham-Rowe, E.; Jessop, D.C.; Sparks, P. Identifying motivations and barriers to minimising household food waste. Resour. Conserv. Recy. 2014, 84, 15-23.

34. Lebersorger, S.; Schneider, F. Discussion on the methodology for determining food waste in household waste composition studies. Waste Manag. 2011, 31, 1924-1933.

35. Lee, P.; Willis, P. Final Report-Waste Arisings in the Supply of Food and Drink to Households in the UK; Waste \& Resources Action Programme (WRAP): Banbury, UK, 2010.

36. Forsa (Gesellschaft für Sozialforschung und Statistische Analysen mbH). Der Wert von Lebensmitteln-Umfragen im Auftrag des BMELV. 2011. Available online: http://www.bmel.de/ SharedDocs/Downloads/Presse/ForsaUmfrageWertVonLM.pdf?_blob=publicationFile (accessed on 12 January 2015). (In German) 
37. Priefer, C.; Jörissen, J.; Bräutigam, K.-R. Technology Options for Feeding 10 Billion People-Options for Cutting Food Waste. Report Prepared for STOA, the European Parliament Science and Technology Options Assessment Panel; Institute for Technology Assessment and Systems Analysis (ITAS) Karlsruhe Institute of Technology (KIT): Württemberg, Germany, 2013.

38. Van Westerhoven, M. Bepaling Voedselverliezen in Huishoudelijk Afval in Niederland-Vervolgmeting 2013; CREM rapport nr. H13; CREM BV: Amsterdam, The Netherlands, 2013. (In Dutch)

39. Elmadfa, I. European Nutrition and Health Report 2009; Elmadfa, I., Ed.; Forum Nutrition Basel, Karger: Basel, Switzerland, 2009; Volume 62, pp. 1-11.

40. Trichopoulou, A.; Soukara, S.; Vasilopoulou, E. Traditional foods: A science and society perspective. Trends Food Sci. Technol. 2007, 18, 420-427.

41. Naska, A.; Fouskakis, D.; Oikonomou, E.; Almeida, M.; Berg, M.; Gedrich, K.; Moreiras, O.; Nelson, M.; Trygg, K.; Turrini, A.; et al. Dietary patterns and their socio-demographic determinants in 10 European countries: data from DAFNE databank. Eur. J. Clin. Nutr. 2006, 60, 181-190.

42. Schmidhuber, J.; Traill, W.B. The changing structure of diets in the European Union in relation to healthy eating guidelines. Public Health Nutr. 2006, 9, 584-595.

43. Quested, T.; Johnson, H. Final Report-Household Food and Drink Waste in the UK; Waste \& Resources Action Programme (WRAP): Banbury, UK, 2009.

44. Wassermann, G.; Schneider, F. Edibles in household waste. In Proceedings of the Tenth International Waste Management and Landfill Symposium, Pula, Sardinia, Italy, 3-5 October 2005; Cossu, R., Stegmann R., Eds.; 2005; pp. 913-914.

45. Parfitt, J.; Barthel, M.; Macnaughton, S. Food waste within food supply chains: Quantification and potential for change to 2050. Phil. Trans. R. Soc. B 2010, 365, 3065-3081.

46. FUSIONS. About FUSIONS. Available online: http://www.eu-fusions.org/what-is-fusions (accessed on 8 January 2015).

(C) 2015 by the authors; licensee MDPI, Basel, Switzerland. This article is an open access article distributed under the terms and conditions of the Creative Commons Attribution license (http://creativecommons.org/licenses/by/4.0/). 